\title{
A Study of Pre-Discharge Holter Monitoring in Patients of Acute Myocardial Infarction
}

\author{
Jalaly $T^{1}$, Uraiya $D^{2}$, Chanchlani $R^{3}$ \\ ${ }^{1}$ Dr Tariq Jalaly, Associate Professor, Department of Medicine, Chirayu Medical College \& Hospital, Bhopal, M.P, ${ }^{2}$ Dr D \\ Uraiya, Assistant Professor, Department of Medicine, Hind Institute of Medical Science, Safedabad, barabanki, UP, India, \\ ${ }^{3}$ Dr Roshan Chanchlani, Associate Professor, Department of Surgery, Chirayu Medical College \& Hospital, Bhopal, M.P, \\ India.
}

Address for Correspondence: Dr Roshan Chanchlani, Email: roshanchanchlani@gmail.com

\begin{abstract}
Background: Increasing array of medical intervention available to modify the likelihood of developing recurrent episode of myocardial ischemia, it is important to identify patients of risk of provocable myocardial ischemia before discharge. Material Methods: It was a cross-sectional study carried out in a tertiary care hospital of central India, during July 2012 to October 2014. During the monitoring period, the patient was once subjected for 100-meter brisk walk. Result: Out of 64 cases, 6 (9.5\%) cases developed ischemia during Holter, in male it was 5(10.2\%) while in female it was $1(6.67 \%)$. $13.33 \%$ of cases with tobacco consumption developed ischemia on Holter monitoring and this was found to statistically significant $\left(x^{2}=5.36, \mathrm{p}<0.05\right)$. Conclusion: After acute myocardial infarction, pre-discharge Holter monitoring (including brisk walk) is a good non-invasive method to detect ischemia in high risk patients (like consuming tobacco in any form).
\end{abstract}

Keywords: Holter Monitoring, Myocardial Infarction, Tobacco

\section{Introduction}

Acute myocardial infarction (MI) continues to be a major health problem. Although the death rate has declined from $30 \%$ to $7.5 \%$, in present era it is still fatal event in approximately one third of the patients [1]. Because acute myocardial infarction strikes an individual during the most productive years, it can have profound delirious psychological and economic ramification. The most important determinant of prognosis after acute myocardial infarction are left ventricular function, occurrence of ventricular arrhythmias, extent of coronary artery disease and myocardial ischemia [2-4].

Given the increasing array of pharmacological intervention catheterization and surgical operation available to modify the likelihood of developing recurrent episode of myocardial ischemia, it is important to identify patients of risk of provocable myocardial ischemia before discharge. A pre-discharge evaluation for ischemia allows clinician to select patients who might benefit from catheterization and revascularization after acute myocardial infarction and

Manuscript received: $22^{\text {nd }}$ Dec 2014

Reviewed: $6^{\text {th }}$ Jan 2015

Author Corrected: $14^{\text {th }}$ Jan 2015

Accepted for Publication: $27^{\text {th }}$ Jan 2015 to asses the adequacy of medical therapy for those patients who are more suitable for conservative management. During the last few decades, for the detection of myocardial ischemia, many non-invasive methods have been used like stress thallium-201 scintigraphy, stress echocardiography, exercise electrocardiography, ambulatory electrocardiography etc, but the principal method of finding the post myocardial infarction ischemia related is exercise stress test [5]. Ambulatory ST-T segment monitoring is a reliable means of detecting myocardial ischemia during daily life in patients with coronary artery disease [6].

The episode of silent myocardial ischemia typically outnumbers the episode accompanying angina [7]. 81\% to $100 \%$ of the ischemic episodes recorded by Holter monitoring are asymptomatic [8] and when compared to exercise testing, the additional prognostic information of Holter monitoring is limited [5]. In patients who are able to do pre-discharge exercise stress test, ambulatory monitoring is considered less sensitive in detecting patients with ST segment depression [8]. These results suggest that the ambulatory ST segment monitoring should not be used as a routine screening test for

Available online at: www.ijmrr.in 85 | P a g e 
Research Article

continuous ischemia in early post infarction period. In the present study, we had tried to increase the sensitivity of ambulatory ECG monitoring for ischemia episode by introducing a 100- meter brisk walk during Holter monitoring. Finally, the aim of the study was to determine that with addition of 100 meter brisk walk, whether pre-discharge Holter monitoring can be taken for pre-discharge sub-maximal exercise stress test for the detection of ischemia after acute myocardial infarction in patients who are not fit for stress test, to determine the baseline characteristics of survivors of acute myocardial infarction and its correlation with transient ischemia on holter recording.

\section{Material and Methods}

The present longitudinal study was carried out in the medicine department in a tertiary care hospital of central India, during the period of July 2012 to October 2014. After the ethical committee approval all the cases during the study period fulfilling the inclusion and exclusion criteria were included in the study.

The inclusion criteria were, those who had acute myocardial infarction suggested by 12 lead ECG were included in the study. Electrocardiographic diagnosis for acute myocardial infarction was made as when:- ST elevation more than $2 \mathrm{~mm}$, or abnormal Q wave $>2 \mathrm{~mm}$ $>25 \%$ of $\mathrm{R}$ wave in same lead, or QS complex. Right ventricular infarction was diagnosed when: - ST elevation in V1 $(>1 \mathrm{~mm}) \mathrm{V}_{4} \mathrm{R}-\mathrm{V}_{6} \mathrm{R}$ or ST depression in $\mathrm{V}_{2}<50 \%$ of ST elevation in a aVF or ECG evidence of inferior wall or inferior posterior wall infarction. Electrocardiographic evidence of sub endocardial infarction was - ST depression and deep inverted T wave in mild precordial leads (symmetrically) lead I and II.

Exclusion criteria were- patient that were unable to ambulate - cerebrovascular accident, cardiac failure (NYHA-IV) on the day of test or those denying a written consent for Holter monitoring or patient presenting with Left Bundle Branch Block(LBBB).

After confirmation of diagnosis of acute myocardial infarction these patients were treated by Nitroglycerin, Aspirin, Heparin, clopidrogel along with conventional symptomatic drugs for pain relief etc. Thrombolytic therapy was given in appropriate cases. Before the patients were discharged all the patients were subject to 24 hours Holter monitoring after the written informed consent. The Digi track plus Holter monitoring was Used. It was a battery operated solid state recorder for 24 to 48 hours of continuous recording for ambulatory patients. It was a 3 channel frequency modulated, with frequency response of 0.05 hertz to 60 hertz. Patient was given a diary in which he/she had to maintain full record of his/her symptoms, activity and time during the monitoring period. Event signal button was explained to the patient. During the monitoring period, the patient was once subjected for 100-meter brisk walk. Patient was asked to walk to his/her maximum speed and try to complete 100 meter as early as he/her could (1 to 3 minute). Patients were instructed to give up the walk if any symptoms like chest pain, palpitation, perspiration and 'ghabrahat' arose. After the walk patient's vitals were examined and were kept under observation for at least one hour or more as required.

All the Holter equipment performed in accordance with the American Heart Association specification with respect to the rate and frequency response necessary to record ST segment alteration reliability. The Zymed Holter Scaner for window 1810 scans a 24 hours ambulatory ECG; detect arrhythmia and ST segment changes and heart rate variability.

Report include the cover page, documented electrocardiographic strips, supraventricular and ventricular arrhythmia summary, ST changes summary, heart rate variability and QRS morphology description is prepared which was then scanned manually and final reporting was done.

The collected data were entered and analyzed using Microsoft office window excel 2007 and SPSS version 16 (SPSS 16.0 for Windows, release 16.0.0. Chicago: SPSS Inc). Frequencies of all variables were taken to check frequencies. To show the association or difference for categorical data chi square test was applied. We considered the association or difference to be significant when the $\mathrm{p}$ value was less than 0.05 .

\section{Result}

The study comprised of 64 cases of acute myocardial infarction brought to intensive coronary care unit. These patients underwent 24 hours Holter monitoring $8 \pm 3$ days after acute myocardial infarction. In the present study out of total 64 cases, there were $40(62.5 \%)$ cases of Anterior wall MI (AWMI), 16 (25\%) cases of Inferior wall MI and $8(12.5 \%)$ cases of combined MI, with more or less equal distribution among male and females. $4(10 \%)$ cases of AWMI developed ischemia, 1(6.25\%) cases of IWMI and one (12.5\%) case of combined (anterior + inferior) MI developed ischemia. Out of 64 cases, $6(9.5 \%)$ cases developed ischemia during Holter, in male it was $5(10.2 \%)$ while in female it was $1(6.67 \%)$.

Available online at: www.ijmrr.in 86 | P a g e 


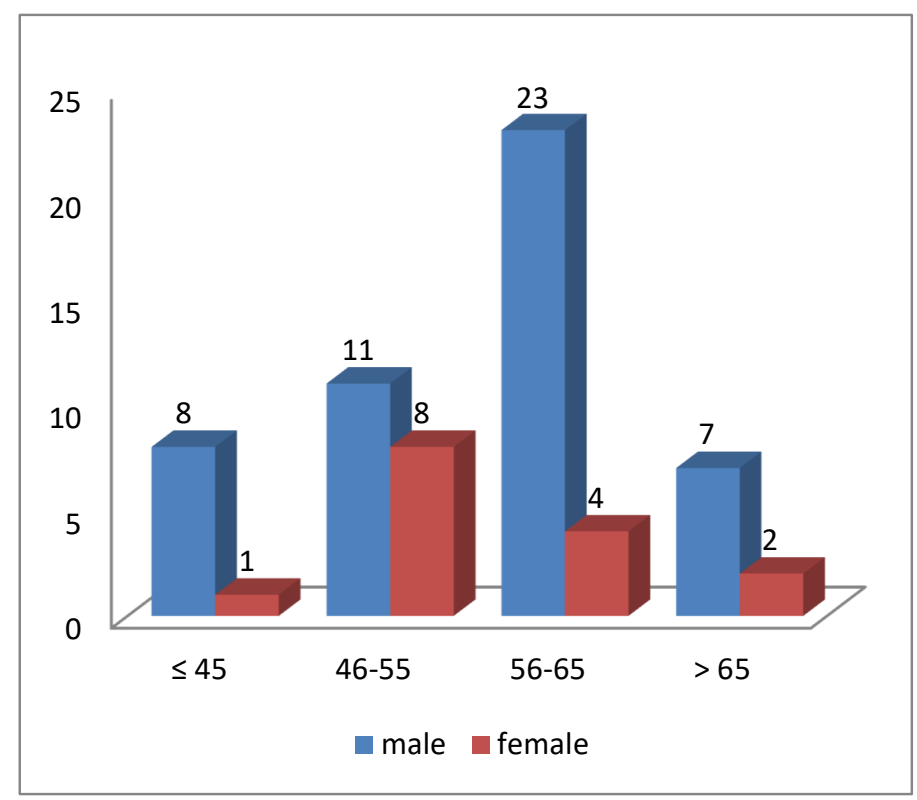

Maximum numbers of patient were observed in the age range 56-65 years comprising $42.1 \%$ (27 cases) of the total Fig. 1. There were $49(76.5 \%)$ males and $15(23.5 \%)$ females.

Table No.1 Association of type of MI with ischemia recoded during Holter monitoring

\begin{tabular}{|l|c|c|c|}
\hline \multirow{2}{*}{ Type of MI } & \multirow{2}{*}{ Total(n=64) } & \multicolumn{2}{c|}{ Ischemia during Holter monitoring } \\
\cline { 3 - 4 } & & No. & \multicolumn{1}{c|}{} \\
\hline AWMI & 40 & 4 & 6.25 \\
\hline IWMI & 16 & 1 & 12.5 \\
\hline combined (AWMI + IWMI) & 8 & 1 & $\mathbf{9 . 4}$ \\
\hline Total & $\mathbf{6 4}$ & $\mathbf{6}$ & \\
\hline
\end{tabular}

Table no. 1 shows AWMI had significant number of cases 4 developed ischemia on holter $\left(x^{2}=17.55, \mathrm{p}<0.001\right)$.

Table No. 2 Association of tobacco consumption with ischemia recoded during holter monitoring

\begin{tabular}{|l|c|c|c|c|}
\hline \multirow{2}{*}{ Tobacco consumption } & \multicolumn{2}{|c|}{ Total( $\mathbf{n = 6 4 )}$} & \multicolumn{2}{c|}{ Ischemia during Holter monitoring } \\
\cline { 2 - 5 } & No. & $\%$ & No. & $\%$ \\
\hline Present & 45 & 70.3 & 6 & 13.33 \\
\hline Absent & 19 & 29.7 & 0 & 0 \\
\hline
\end{tabular}

$x^{2}=5.36, \mathrm{p}<0.05$

It is evident from table that tobacco consumption was found to statistically significant association with ischemia. $\left(x^{2}=\right.$ $5.36, \mathrm{p}<0.05)$

Among the study subjects hypertension was the commonest associated past history comprising 11 cases (17.2\%), out of them, 2 cases (18.18\%) developed ischemia during holter monitoring. Six (9.4\%) cases among the study subject had past history of diabetes mellitus and none developed ischemia during monitoring. Four cases had past history of both diabetes mellitus and hypertension and out of these 4 cases 1 (25\%) developed ischemia during holter monitoring. Among the total, 5 cases $(7.8 \%)$ had past history of ischemic heart disease and among them 1 case (20\%) developed ischemia during holter monitoring. Tobacco consumption in any form was observed in $45(70.3 \%)$ cases, interestingly all cases $6(100 \%)$ who developed ischemia during holter were consuming tobacco in any form. Table no. 2 shows $13.33 \%$ of cases with tobacco consumption developed ischemia on Holter monitoring and this was found to statistically significant $\left(x^{2}=5.36\right.$, $\mathrm{p}<0.05)$ 


\section{Discussion}

Ischemia following acute myocardial infarction is a known phenomenon. It may be symptomatic or asymptomatic. With the technical development in ambulatory ECG (Holter), for the measurement of ST segment alteration it is possible to detect episodes of ischemia more accurately. It is well known fact that exercise stress ECG, thallium scintigraphy, radionuclide ventriculography or echocardiography are methods for detecting ischemia in post infarction patients. Present study consisted of 64 cases of acute myocardial infarction admitted in medicine department of tertiary care institute of central India. Out of 64 cases, ischemia was recorded in 6 cases $(9.4 \%)$. Out of these 6 cases, 4 cases were of AWMI (66.6\%) and 1 (16.7\%) each of IWMI and combined MI (AWMI + IWMI). Similarly Astrall et al [9] reported $\mathrm{MI}$ in $14 \%$ of their patients and in another study Curie P [10] also reported 14\%. The reported incidence of ambulatory ECG ischemia after acute MI ranges from 8 to $46 \%[11,12]$. In these studies Holter monitoring was performed as early as 3 days or as late as 2 years after acute myocardial infarction. In the present study, patients were receiving low molecular weight heparin as well as anti-ischemic treatment. Patients were in ICCU and restricted to bed for most of the time. Maximum patients were from 56-65 years of age, comprising of 27 (42.8\%) out of 64 cases. John B et al studied that maximum cases were from $\geq 65$ years [13]. Out of 15 females, only 1 was under 45 years of age while 14 out of $15(93.3 \%)$ were above 45 years. Possible explanation of higher number of cases in postmenopausal age may be role of hormone. Ischemia was seen more in $>65$ years age group two $(28.6 \%)$ of 7 patients in this age group developed ischemia during Holter monitoring which was comparable to Arstall et al,[9] who reported that the average age was $65 \pm 4$ years in patients who developed ischemia during Holter monitoring. Decades of observation studies have verified excess coronary risk in males. In the present study out of 64 cases, 49 patients $(76.6 \%)$ were male while $15(23.4 \%)$ were female. The ratio of male to female was $3.3: 1$. Out of 6 patients who developed ischemia, 5 were male $(83.3 \%)$ while 1 was female $(16.7 \%)$. The cause of higher proportion of ischemia among males could be their association with other risk factor like higher tobacco consumption as compared to female. In the present study, past history of associated illness was given by $37.5 \%$ (24 out of 64 patients) cases. Hypertension was the most common risk factor other

than tobacco consumption 11 cases $(17.2 \%)$ were having hypertension, $6(9.4 \%)$ had diabetes
mellitus(DM) and 4 cases $(6.3 \%)$ with both diabetes mellitus and Hypertension(HT). 5 cases (7.8\%) had positive family history of DM, HT and/or ischemic heart disease. Ischemia was recorded in $2(18.8 \%)$ of the 11 hypertensive patients which is comparable to Astrall et al [9], who observed ischemia in $17 \%$ of HT cases. None of the DM patients developed ischemia during Holter monitoring which is comparable to Astrall et al, [9] who did not find ischemia in his diabetic cases during Holter recording. One out of 4 cases $(25 \%)$ that suffered from DM and HT developed ischemia during Holter monitoring. $20 \%$ cases ( 1 out of 5 ) with history of ischemic heart diseases developed ischemia during Holter monitoring. Astrall et al reported ischemia in $50 \%$ cases of unknown ischemic heart diseases cases [9]. This difference in the findings could be due to illiteracy as patients go to quacks, who treat them symptomatically and patients never know that they have ischemic heart disease. Tobacco consumption in any form of smoking and chewing constitutes the single most important modifiable risk factor for coronary artery diseases. In the present study, $70.3 \%$ of cases (45 out of 64) were consuming tobacco in some or the other form, it was comparable to $69 \%$ as observed by Astrall et al [9]. This shows that the tobacco consumption is highly significant risk factor to coronary artery disease. All the 6 patients $(100 \%)$ who developed ischemia during Holter monitoring were consuming tobacco (including female). Mickley $\mathrm{H}$ et al. in their study observed $78 \%$ cases of ischemia were consuming tobacco [8].

\section{Conclusion}

After acute myocardial infarction, pre-discharge Holter monitoring (including brisk walk) is a good noninvasive method to detect ischemia in high risk patients (like consuming tobacco in any form).

Funding - NIL

Permission from IRB - Yes

Conflicts of interest - The authors report no conflicts of interest

\section{References}

1. Joseph SA and Garry SF. Cited at Hand book of coronary care. $6^{\text {th }}$ edition, willy publication.2000: 15 107

\begin{tabular}{lrrr}
$2 . \quad$ Bigger & \multicolumn{2}{c}{ JT Jr, Fleiss JL, Kleiger } & R, Miller \\
JP, Rolnitzky & LM. The relationships & among
\end{tabular} 
ventricular arrhythmias, left ventricular dysfunction, and mortality in the 2 years after myocardial infarction. Circulation. 1984 Feb; 69(2):250-8.

3. Taylor GJ, Humphries JO, Mellits ED, Pitt B, Schulze RA, Griffith LS, Achuff SC. Predictors of clinical course, coronary anatomy and left ventricular function after recovery from acute myocardial infarction.

Circulation. 1980 Nov;62(5):960-70

4. Multicentric Post Infarction Research group. Risk stratification and survival after acute myocardial infarction. N Engl J Med. 1983 Aug 11;309(6):331-6.

5. Jereczek M, Dietrich A and Joahchim S. Prognostic value of ischemia during Holter monitoring and exercise testing after acute myocardial infarction. Am J Cardiol. 1993 Jul 1;72(1):8-13.

6. Deanfield JE, Maseri A, Selwyn AP And Morgan M. Myocardial ischemia during daily life in patients with stable angina: its relation to symptoms and heart rate change. Lancet. 1983 Oct 1;2(8353):753-8.

7. Tzivoni D, Gavish A Zin D, Gottlieb S and Morel M. Prognostic significance of ischemia episodes in patients with previous myocardial infarction. Am J Cardiol 1988; 62: 661-664
8. Mickley H. Editorial: Amulatory ST segment monitoring after myocardial infarction. Br Heart J. 1994 Feb;71(2):113-4.

9. Arstall MA, Barromer FA, Horonitz JD. Silent ischemia after uncomplicated myocardial infarction: lack of clinical significance. Int J Cardiol. 1994 Jun $1 ; 45(1): 45-52$.

10. Currie P, Ashby D, Saltissi S. Prognostic significance of transient myocardial infarction on ambulatory monitoring after acute myocardial infarction. Am J Cardiol. 1993 Apr 1;71(10):773-7.

11. Chaitman B, McMohan RP, Terin M. Impact of treatment strategy on predischarge exercise test to the thromolysis in myocardial infarction. (TIMI) II Trial. Am J Cardiol. 1993 Jan 15;71(2):131-8.

12. Gottlieb SO, Weisfeldt ML, Ouyang P, Mellitis ED. Silent ischemia predict infarction and death during 2 years follow up of unstable angina. J Am Coll Cardiol. 1987 Oct;10(4):756-60.

13. John BG, Cairns JA, Roberts M. Prognostic importance of myocardial ischemia detected by ambulatory monitoring early after acute myocardial infarction: India. N Engl J Med. 1996 Jan 11;334(2):6570 .

\section{How to cite this article?}

Jalaly T, Uraiya D, Chanchlani R. A Study of Pre-Discharge Holter Monitoring in Patients of Acute Myocardial Infarction. Int J Med Res Rev 2015;3(1):85-89. doi: 10.17511/ijmrr.2015.11.14 